\title{
Basic and clinical immunology - 3031. The correlation between serum protemics patterns of sTRAIL and CXCL8 with FDG-PET/CT findings in bevacizumab treated colon cancers
}

\author{
Arzu Didem Yalcin ${ }^{1 *}$, Atil Bisgin ${ }^{2}$, Aysegul Kargi $^{3}$, Burhan Savas $^{4}$, Metin Erkilic ${ }^{5}$, Antonia Dimitrakopoulou-Strauss ${ }^{6}$, \\ Ludwig Strauss ${ }^{6}$
}

From 2nd WAO International Scientific Conference (WISC 2012)

Hyderabad, India. 6-9 December 2012

\section{Background}

Bevacizumab is a humanized monoclonal antibody developed against vascular endothelial growth factor (VEGF) for the treatment of metastatic colorectal cancer (MCRC). The changes and correlations of STRAIL and CXCL8 prior to treatment and three months following therapy as well as the corresponding Positron emission tomography (18FDG-PET/CT) results were evaluated.

\section{Methods \\ The measurements were taken before and after treatment for comparison purposes. The study population com- prised 17/29 patients with MCRC, undergoing PET/CT scanning prior to treatment. We were able to perform a follow up PET/CT examination three months after onset of therapy in $15 / 17$ patients.Patients were instructed to fast for at least $6 \mathrm{~h}$ before an injection of 18F-FDG (5 MBq/kg)(GeminiPET/CTsystem). Images were recon- structed using the maximum-likelihood 3-dimensional algorithm according to standard clinical protocol: 2 itera- tions,relaxation parameter of 0.05,5-mm,3-dimensional gaussian postfiltering, a4.4.4mm-voxel grid sampling, and attenuation correction based on a low-dose CT scan.All images were visually interpreted by consensus between two experienced nuclear physicians and standardized uptake values $\left(\mathrm{SUV}_{\max }\right)$ were calculated from the image data.}

\section{Results}

There were significant changes prior to treatment and three months later for sTRAIL $(\mathrm{p}=0.0080)$ and CXCL8 $(\mathrm{p}=0.0001)$. Generally, sTRAIL values were increasing during therapy, while a decrease was observed for CXCL8. Correlation analysis was applied to the data and revealed significant correlations for the $\mathrm{SUV}_{\max }$ in the primary tumor prior to treatment and CXCL8 prior to therapy $(\mathrm{p}=0.0303)$. Furthermore, significant correlations were observed for the $\mathrm{SUV}_{\max }$ and $\operatorname{sTRAIL}(\mathrm{p}=0.0237)$ as well as CXCL8 $(\mathrm{p}=0.0002)$ three months after treatment initiation. CXCL8 prior to treatment was also correlated with the SUV three months after onset of treatment $(p=0.0072)$. A significant correlation was noted for one combination of two variables, the $\mathrm{SUV}_{\max }$ in the metastases and CXCL8 prior to treatment $(\mathrm{p}=0.0175)$. These results are supported when we group the $\mathrm{SUV}_{\max }$ in the metastases following treatment into two groups with $\mathrm{SUV}_{\text {max }}<5$ and $\mathrm{SUV}_{\text {max }}>5$. There is a significant difference for both groups regarding overall survival, with a lower survival associated with $\mathrm{SUV}_{\max } \mathrm{s}$ exceeding.

\section{Conclusions}

This study provides evidence that proteomics patterns of sTRAIL and CXCL8 predict tumor response und survival in MCRC patients treated with bevacizumab and within a high concordance of 18-FDG-PET/CT findings. The high correlation of CXCL8 and FDG uptake in metastases prior to treatment with survival direct to a promising approach to individualize treatment of patients.

(c) 2013 Yalcin et al; licensee BioMed Central Ltd. This is an Open Access article distributed under the terms of the Creative Commons 


\section{Author details}

${ }^{1}$ Internal Medicine, Allergy and Immunology, Education and Research Hospital, Turkey. ${ }^{2}$ Cancer institue., Sweden. ${ }^{3}$ Department of Internal Medicine, Antalya Education and Research Hospital, Antalya, Turkey. ${ }^{4}$ Department of Internal Medicine, Oncology Unit, Akdeniz University Hospital, Antalya, Turkey. ${ }^{5}$ Department of Nuclear Medicine, Akdeniz University Hospital, Turkey. ${ }^{6} \mathrm{Clinical}$ Cooperation Unit Nuclear Medicine, German Cancer Research Center, Im Neuenheimer Feld 280, 69120, Heidelberg, Germany.

Published: 23 April 2013

doi:10.1186/1939-4551-6-S1-P206

Cite this article as: Yalcin et al:: Basic and clinical immunology - 3031 .

The correlation between serum protemics patterns of sTRAIL and

CXCL8 with FDG-PET/CT findings in bevacizumab treated colon cancers.

World Allergy Organization Journal 2013 6(Suppl 1):P206.

\section{Submit your next manuscript to BioMed Central} and take full advantage of:

- Convenient online submission

- Thorough peer review

- No space constraints or color figure charges

- Immediate publication on acceptance

- Inclusion in PubMed, CAS, Scopus and Google Scholar

- Research which is freely available for redistribution

Submit your manuscript at www.biomedcentral.com/submit 